\title{
Solvothermal Synthesis of Gallium and Indium Nitrides Using Lithium Amide
}

\author{
Pietro Chirico and Andrew L. Hector \\ School of Chemistry, University of Southampton, Highfield, Southampton SO17 1BJ, U. K. \\ Reprint requests to Dr A. L. Hector. E-mail: a.1.hector@soton.ac.uk
}

Z. Naturforsch. 2010, 65b, 1051 - 1057; received March 27, 2010

\begin{abstract}
Results of the investigation of the reactions of $\mathrm{GaCl}_{3}, \mathrm{InCl}_{3}$ and $\mathrm{InI}_{3}$ with $\mathrm{LiNH}_{2}$ under solvothermal conditions in benzene, which lead to metal nitrides, are reported. GaN is obtained as a cubic phase or as a mixture of cubic and hexagonal phases, depending on temperature. The effect of the addition of surfactants on the formation of $\mathrm{GaN}$ was explored. InN products were always contaminated with indium metal, even at low reaction temperatures. The addition of excess $\mathrm{LiNH}_{2}$ or the use of $\mathrm{InI}_{3}$ instead of $\mathrm{InCl}_{3}$ gave products with less In metal.
\end{abstract}

Key words: Gallium Nitride, Indium Nitride, Nanocrystal, Solvothermal Synthesis

\section{Introduction}

Gallium and indium nitrides are important optoelectronic materials with band gaps ranging from $0.7 \mathrm{eV}$ in $\mathrm{InN}$ to $3.4 \mathrm{eV}$ in $\mathrm{GaN}$. $\mathrm{GaN}$ is especially relevant as, with the introduction of suitable dopants or in solid solution with InN, its band gap can be varied to emit light from the UV to the IR region. When used in electronic devices, these nitrides are typically produced using MOVPE or MOCVD techniques [1]. They have also been prepared in powdered form by high-temperature ammonolysis [2] or metal amide decomposition [3], and as nanoparticle colloids by decomposition of molecular precursors in hot solvents [4]. Solvothermal synthesis is gradually developing into a useful technique to produce metal nitrides in nanocrystalline form [5], including anisotropic particles. Typically the reagents are those that have previously been used in solid-state metathesis, especially metal chlorides and $\mathrm{Li}_{3} \mathrm{~N}$ or $\mathrm{NaN}_{3}$ [6]. Nanocrystalline $\mathrm{GaN}$ has been produced from $\mathrm{Li}_{3} \mathrm{~N}$ and $\mathrm{GaCl}_{3}$ in benzene at $280{ }^{\circ} \mathrm{C}$ [7] as nanocrystals of $\sim 30 \mathrm{~nm}$ diameter. Under these conditions a mixture of hexagonal and rocksalt-type $\mathrm{GaN}$ was produced. This was surprising as rocksalt-type $\mathrm{GaN}$ is normally only found at high pressure [8]. $\mathrm{GaCl}_{3}$ and $\mathrm{NaN}_{3}$ react in toluene or THF at $260{ }^{\circ} \mathrm{C}$, producing a poorly crystalline product [9], but on annealing to $750{ }^{\circ} \mathrm{C}$ hexagonal GaN crystals of $\sim 8 \mathrm{~nm}$ size were produced. Hexagonal $\mathrm{GaN}$ has also been prepared using solvothermal reactions between $\mathrm{Ga}$ cupferron or $\mathrm{GaCl}_{3}$ and $\left(\mathrm{Me}_{3} \mathrm{Si}\right)_{2} \mathrm{NH}$
(HMDS) [10]. In this work the authors added a surfactant ( $N$-cetyltrimethylammonium bromide) and obtained capped nanoparticles. Solvothermal synthesis of InN has been achieved via reactions of $\mathrm{InCl}_{3}$ with $\mathrm{Li}_{3} \mathrm{~N}$ in xylene [11] or of $\mathrm{InI}_{3}$ with $\mathrm{NaNH}_{2}$ in benzene, both at around $250{ }^{\circ} \mathrm{C}$ [12]. Another report showed the reactions between $\mathrm{InBr}_{3}$ and $\mathrm{NaN}_{3}$ in toluene or hexadecane at $\sim 280{ }^{\circ} \mathrm{C}$ to produce $10 \mathrm{~nm}$ hexagonal $\mathrm{InN}$ crystallites, with some evidence of cubic InN at lower temperatures [13].

Recently we have been studying the reactions of transition metal chlorides with $\mathrm{LiNH}_{2}$ and $\mathrm{NH}_{3}$ under solvothermal conditions. We have found that these are effective methods to produce nanocrystalline nitride materials with metals of groups 4, 5 and 6 [14]. In some cases, most extensively with Ta, we have found that nanorods can also be grown under these conditions. In the work described in this paper we examined reactions between gallium and indium chlorides, and indium iodide, with $\mathrm{LiNH}_{2}$ under similar conditions. We also investigated the effect of the addition of surfactants on the synthesis of $\mathrm{GaN}$.

\section{Experimental Section}

All preparations were carried out under anaerobic conditions using either glove box or Schlenk line techniques for sample loading and handling. Benzene was distilled from $\mathrm{Na}$, methanol from $\mathrm{NaOCH}_{3}$, and hexadecylamine (HDA) from $\mathrm{BaO} . \mathrm{GaCl}_{3}(99.999 \%), \mathrm{InCl}_{3}(99.999 \%), \mathrm{InI}_{3}(99.998 \%)$ and $N$-cetyltrimethylammonium bromide $(\mathrm{CTAB} ;>99 \%)$ were purchased from Aldrich and used as supplied. Ammo- 
nia (Air Products) was distilled from a sodium/ammonia solution before use. $\mathrm{LiNH}_{2}$ was synthesised by reacting $1.6 \mathrm{M}$ ${ }^{n} \mathrm{BuLi}$ in hexane (Aldrich) with excess distilled ammonia at $-78{ }^{\circ} \mathrm{C}$, filtering, and drying the product in vacuo.

All syntheses were performed in a $75 \mathrm{~cm}^{3}$ autoclave (Parr $4740 \mathrm{CH})$. Typically, $0.6 \mathrm{~g}$ of metal chloride was placed in the silica liner and covered with $15 \mathrm{~cm}^{3}$ of benzene. A stoichiometric amount of $\mathrm{LiNH}_{2}$, calculated to balance the lithium and chloride components of the reaction mixture, was added. The autoclave was heated at the temperatures detailed later, typically for $24 \mathrm{~h}$. After cooling to r.t., the autoclave was opened, and the mixture was transferred to a Schlenk tube inside the glove box. The solid was collected by filtration, washed with dry methanol three times to remove the $\mathrm{LiCl}$ by-product, and dried in vacuo.

Powder X-ray diffraction (PXD) measurements were performed on a Siemens D5000 diffractometer using $\mathrm{Cu} K_{\alpha 1}$ ( $\lambda=1.5406 \AA$ ) radiation. The phases present were identified by comparison with the JCPDS database [15] and patterns refined using the GSAS package [16]. Crystallite sizes were obtained using the Scherrer formula. Transmission electron microscopy (TEM) was carried out with a Hitachi $7000(75 \mathrm{kV})$ instrument. Samples were prepared by ultrasound dispersal in toluene, followed by deposition on carbon-coated $\mathrm{Cu}$ grids. IR spectra were recorded from CsI disks using a Perkin Elmer Spectrum 100 instrument. TGA data were collected with a Mettler Toledo TGA851e under flowing high-purity nitrogen with a heating rate of $10^{\circ} / \mathrm{min} . \mathrm{C}, \mathrm{H}, \mathrm{N}$ combustion analyses and Schöniger flask combustion analysis of chlorine content were carried out by Medac Ltd. (Egham, Surrey, UK).

\section{Results and Discussion}

\section{Reactions of gallium chloride with lithium amide}

The solvothermal route to GaN nanocrystals in benzene using $\mathrm{LiNH}_{2}$ as the nitrogen source was envisaged to proceed as follows:

$$
\mathrm{GaCl}_{3}+3 \mathrm{LiNH}_{2} \rightarrow \mathrm{GaN}+3 \mathrm{LiCl}+2 \mathrm{NH}_{3}
$$

Samples were prepared at temperatures in the range $250-450{ }^{\circ} \mathrm{C}$. At $250^{\circ} \mathrm{C}$ zinc blende-type (cubic) $\mathrm{GaN}$ was obtained, whereas at higher temperatures a mixture of the zinc blende- and the wurtzite-type (hexagonal) phases formed (Fig. 1). The feature below $25^{\circ}$ in the patterns collected from samples made at 250 $350{ }^{\circ} \mathrm{C}$ is due to some amorphous content, whereas the peak at $26^{\circ}$ is due to pyrolytic carbon produced by solvent decomposition during the reactions. The 220 reflection in the cubic phase does not overlap with other peaks and was used to calculate a lattice parameter of $a=4.46 \AA$ and an average crystallite size
Table 1. The products from reactions of $\mathrm{GaCl}_{3}$ and $\mathrm{LiNH}_{2}$. Analyses are accurate to $\pm 0.3 \%$.

\begin{tabular}{ccccc}
\hline Temperature $\left({ }^{\circ} \mathrm{C}\right)$ & Composition & $\% \mathrm{C}$ & $\% \mathrm{~N}$ & $\% \mathrm{H}$ \\
\hline 450 & $\mathrm{GaN}_{0.69} \mathrm{C}_{0.16}$ & 2.4 & 11.9 & 0.8 \\
400 & $\mathrm{GaN}_{0.68} \mathrm{C}_{0.26}$ & 3.9 & 11.5 & 1.1 \\
350 & $\mathrm{GaN}_{0.69} \mathrm{C}_{0.20}$ & 2.9 & 11.8 & 1.3 \\
300 & $\mathrm{GaN}_{0.70} \mathrm{C}_{0.13}$ & 2.0 & 12.1 & 1.6 \\
250 & $\mathrm{GaN}_{0.70} \mathrm{C}_{0.36}$ & 5.1 & 11.7 & 2.1 \\
\hline
\end{tabular}



Fig. 1. PXD patterns $\left(\mathrm{Cu} K_{\alpha 1}\right)$ of the samples prepared at different reaction temperatures from $\mathrm{GaCl}_{3}$ and $\mathrm{LiNH}_{2}(\bullet=$ reflection positions for wurtzite-type $\mathrm{GaN} ; *$ = positions for the 111,220 and 311 reflections of zinc blende-type GaN; the 200 and 222 peaks are responsible for the asymmetry of the 111 and 311 peaks).

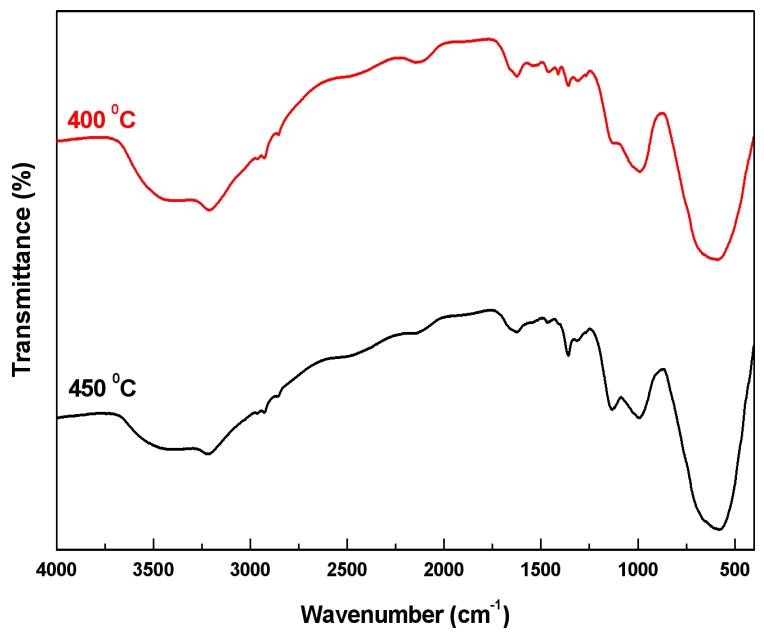

Fig. 2. IR spectra of $\mathrm{GaN}$ produced from $\mathrm{GaCl}_{3}$ and $\mathrm{LiNH}_{2}$ at 400 and $450{ }^{\circ} \mathrm{C}$.

of $1.8 \mathrm{~nm}$. Literature reports of the lattice parameters of GaN range from $4.36-4.47 \AA$ [16]. 


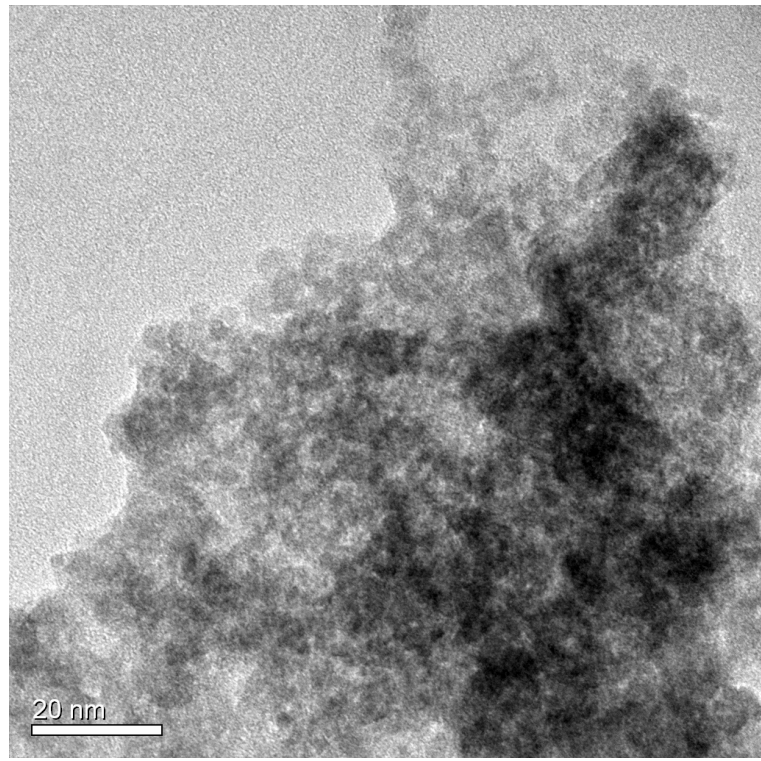

Fig. 3. TEM image of GaN prepared from $\mathrm{GaCl}_{3}$ and $\mathrm{LiNH}_{2}$ at $300{ }^{\circ} \mathrm{C}$.

Combustion analysis revealed nitrogen-deficient GaN samples with significant carbon and hydrogen content (Table 1). A small amount of chlorine $(<5 \%)$ was also found in the products. The IR spectra (Fig. 2) show a broad Ga-N stretch around $600 \mathrm{~cm}^{-1}$ (double peak due to $\mathrm{A}_{1}+\mathrm{E}_{1}$ modes), significant $v(\mathrm{~N}-\mathrm{H})$ and weak $v(\mathrm{C}-\mathrm{H})$ bands [17]. The mechanism of $\mathrm{GaN}$ formation most likely involves metathesis reactions that produce $\mathrm{Ga}-\mathrm{NH}_{2}$ groups that then condense with neighbouring $\mathrm{Ga}$ centres. Hence the presence of residual NH groups in the products at these relatively mild temperatures is not surprising. The decomposition of solvent to produce carbon is less expected. TEM showed regular-shaped crystallites with particle sizes below $5 \mathrm{~nm}$ (Fig. 3). All of the samples studied had significant aggregation of these crystallites.

Reactions between $\mathrm{GaCl}_{3}$ and $\mathrm{LiNH}_{2}$ in the presence of hexadecylamine

The use of surfactants to control the particle size and prevent the agglomeration of nanoparticles is common, and there is one reported example of the production of capped $\mathrm{GaN}$ nanocrystals under solvothermal conditions by adding CTAB [10]. Hence reactions analogous to those described above were tried with added hexadecylamine. Various amounts of HDA were added to reactions between $\mathrm{GaCl}_{3}$ and $\mathrm{LiNH}_{2}$ in ben-
Table 2. Products identified from the reactions of $\mathrm{GaCl}_{3}$ and $\mathrm{LiNH}_{2}$ with added HDA. Combustion analyses are accurate to $\pm 0.3 \%$.

\begin{tabular}{lcccccc}
\hline Composition & $\begin{array}{c}\text { HDA } \\
(\mathrm{mg})\end{array}$ & $\mathrm{C}$ & $\begin{array}{c}\% \\
\mathrm{~N}\end{array}$ & $\mathrm{H}$ & $\begin{array}{c}\text { Crystallite size } \\
(\mathrm{nm})\end{array}$ & $\begin{array}{c}a \\
(\AA)\end{array}$ \\
\hline $\mathrm{GaN}_{0.17} \mathrm{C}_{0.93}$ & 200 & 13.4 & 2.9 & 3.4 & 2.0 & 4.48 \\
$\mathrm{GaN}_{0.27} \mathrm{C}_{1.25}$ & 300 & 16.9 & 4.3 & 3.9 & 2.0 & 4.46 \\
$\mathrm{GaN}_{0.50} \mathrm{C}_{2.00}$ & 500 & 23.8 & 7.0 & 4.8 & 1.8 & 4.48 \\
$\mathrm{GaN}_{0.76} \mathrm{C}_{2.73}$ & 700 & 28.9 & 9.5 & 5.4 & 1.8 & 4.48 \\
\hline
\end{tabular}

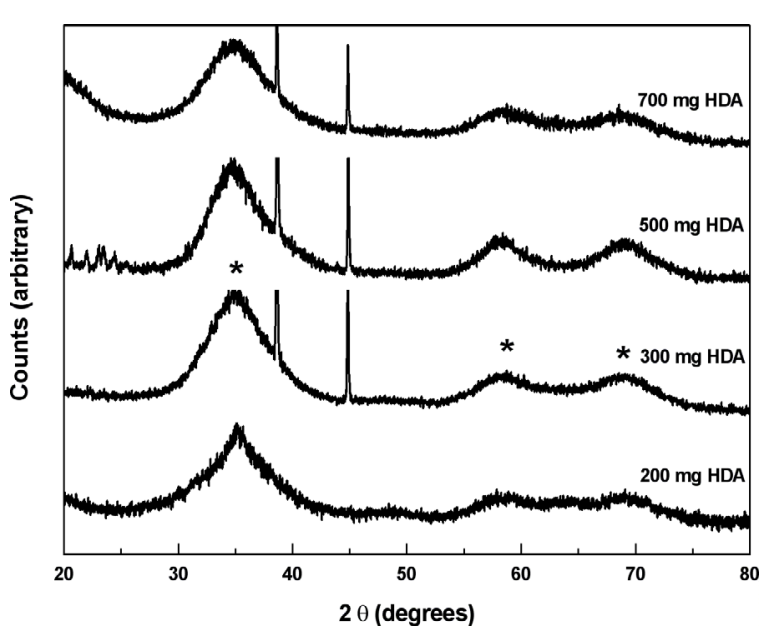

Fig. 4. XRD patterns of samples prepared from $\mathrm{GaCl}_{3}$ and $\mathrm{LiNH}_{2}$ at $250{ }^{\circ} \mathrm{C}$ with different amounts of HDA. The 111, 220 and $311 \mathrm{GaN}$ reflections are marked by asterisks. Two aluminium peaks resulting from the sample holder are visible in some data sets at 38 and $44^{\circ}$.

zene at $250{ }^{\circ} \mathrm{C}$ in an attempt to produce capped particles. PXD data identified all of the products as cubic GaN (Fig. 4). The addition of small amounts of HDA led to a small increase in the crystallite size and a reduction in the amorphous content of the samples. When 300 or $500 \mathrm{mg}$ of HDA was added, the PXD patterns showed very little amorphous scattering. This change suggests that HDA becomes involved in the formation of $\mathrm{GaN}$, possibly reacting more readily with the $\mathrm{GaCl}_{3}$ in solution than does the solid $\mathrm{LiNH}_{2}$. Metal primary amides can self-condense to produce bridging imide groups. This is chemistry that we have used in sol-gel processing of TiN [18]. Addition of further HDA, however, resulted in the reappearance of amorphous features in the diffraction patterns and further broadening of the reflections. The lattice parameters of these samples are a little higher than those of samples produced without HDA and also slightly higher than the normal range of literature values. Carbon incorporation into nitride structures typically results in an increase in the lattice parameter. 


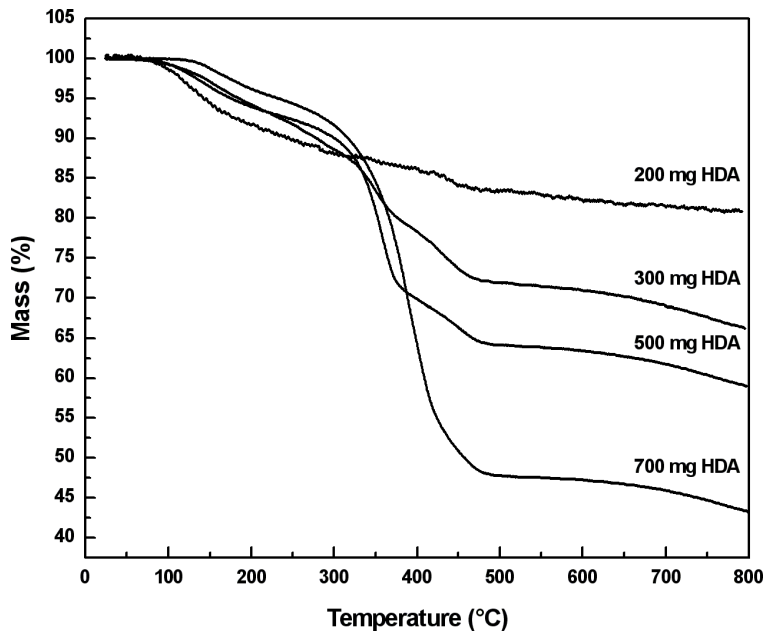

Fig. 5. TGA of samples produced from $\mathrm{GaCl}_{3}$ and $\mathrm{LiNH}_{2}$ with different amounts of HDA.

Carbon incorporation directly into the GaN structure is also consistent with the microanalysis results (Table 2) that show low nitrogen contents ( $\mathrm{GaN}$ contains $16.7 \% \mathrm{~N}$ ) in these samples. The $\mathrm{C}, \mathrm{H}$ and $\mathrm{N}$ contents all increase as more HDA is added to the reactions, showing that it is carried through to the products. The IR spectra showed significant sharp $v(\mathrm{C}-\mathrm{H})$ and broad $v(\mathrm{~N}-\mathrm{H})$ bands, and also broad bands in the $v(\mathrm{Ga}-\mathrm{N})$ region around $600 \mathrm{~cm}^{-1}$ [19]. TGA traces (Fig. 5) showed a feature with an onset around $100{ }^{\circ} \mathrm{C}$ that could be due to loss of benzene that was dissolved in the HDA and hence not removed when the samples were dried in vacuo. Two further major features are then observed with onsets of around 300 and $400{ }^{\circ} \mathrm{C}$. It is likely that the lower temperature mass loss is unbound HDA and the higher temperature one is surfacebound HDA, as the sample with only $200 \mathrm{mg}$ HDA only shows the higher temperature feature. TEM images of these samples were somewhat indistinct, probably due to the HDA coating the spaces between particles, but it was apparent that there was a similar level of aggregation to that observed without HDA.

Reactions between $\mathrm{GaCl}_{3}$ and $\mathrm{LiNH}_{2}$ in the presence of $\mathrm{N}$-cetyltrimethylammonium bromide

CTAB was previously used to cap GaN particles grown in solvothermal reactions between gallium cupferron and hexamethyldisilazane in toluene [10]. Addition of CTAB to the reactions between $\mathrm{GaCl}_{3}$ and $\mathrm{LiNH}_{2}$ resulted in PXD patterns similar to those observed with added HDA (Fig. 6). Small quantities re-
Table 3. Compositions and structural data for products of the reactions of $\mathrm{GaCl}_{3}$ and $\mathrm{LiNH}_{2}$ using different amounts of CTAB. Combustion analyses are accurate to $\pm 0.3 \%$.

\begin{tabular}{lcccccc}
\hline Composition & $\begin{array}{c}\text { CTAB } \\
(\mathrm{mg})\end{array}$ & $\mathrm{C}$ & $\mathrm{N}$ & $\mathrm{H}$ & $\begin{array}{c}\text { Crystallite size } \\
(\mathrm{nm})\end{array}$ & $\begin{array}{c}a \\
(\AA)\end{array}$ \\
\hline $\mathrm{GaN}_{0.73} \mathrm{C}_{0.37}$ & 300 & 5.3 & 12.1 & 2.2 & 1.8 & 4.49 \\
$\mathrm{GaN}_{0.61} \mathrm{C}_{0.37}$ & 500 & 5.3 & 10.3 & 2.3 & 2 & 4.51 \\
& 700 & - & - & - & 1.8 & 4.50 \\
\hline
\end{tabular}

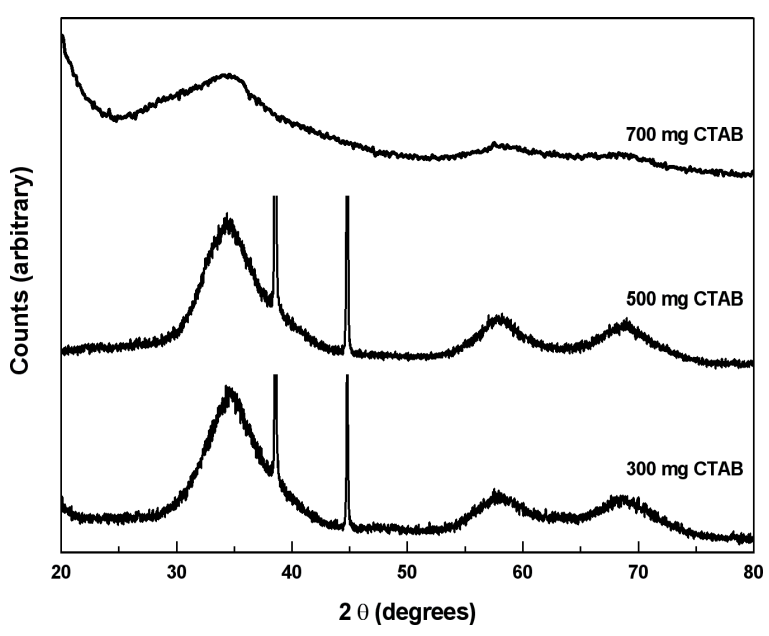

Fig. 6. PXD patterns of the products from the reactions of $\mathrm{GaCl}_{3}$ with $\mathrm{LiNH}_{2}$ using different amounts of CTAB. Sharp peaks at 38 and $44^{\circ}$ are due to the $\mathrm{Al}$ sample holder.

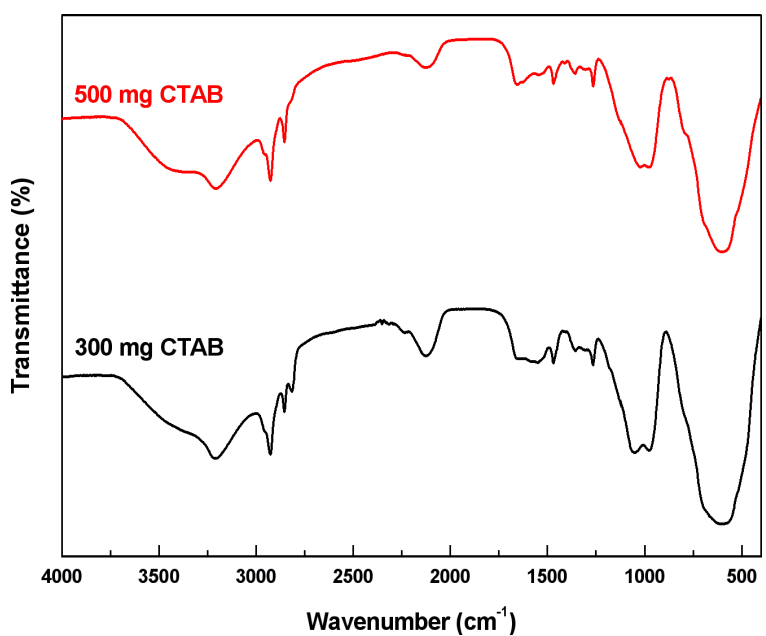

Fig. 7. IR spectra of the products of reactions of $\mathrm{GaCl}_{3}$ with $\mathrm{LiNH}_{2}$ using different amounts of CTAB.

sulted in a reduction in the amorphous content of the samples, but with larger additions the amorphous features returned to the PXD patterns. Lattice parameters (Table 3) were slightly high, again probably reflecting some carbon incorporation. Interestingly 


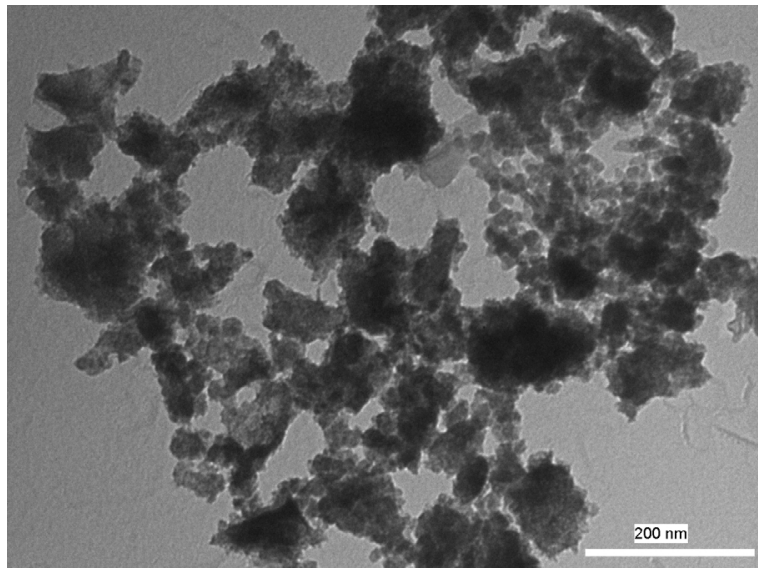

Fig. 8. TEM image of $\mathrm{GaN}$ produced from $\mathrm{GaCl}_{3}$ and $\mathrm{LiNH}_{2}$ with $500 \mathrm{mg}$ added $\mathrm{CTAB}$.

the composition of the products varied less with the amount of CTAB, and the nitrogen content was higherpresumably the higher solubility of CTAB than that of HDA in benzene and methanol allows more efficient removal of the former. The TGA traces were also very similar for samples made with different amounts of CTAB. IR spectra (Fig. 7) contained a strong $v$ (GaN) band at $\sim 600 \mathrm{~cm}^{-1}$ and features corresponding to $v(\mathrm{C}-\mathrm{H})$ and $v(\mathrm{~N}-\mathrm{H})$, the relative strength of these features also being very similar however much CTAB was added to the reaction mixture. Disappointingly TEM images still showed significant aggregation in these samples, though there was some evidence of individual particles (Fig. 8).

\section{Reactions of indium chloride and iodide with lithium amide}

Due to its low thermal stability $[19,20]$, InN is more difficult to synthesise than GaN. Our aim was the preparation of InN by methods analogous to those described above for GaN:

$$
\mathrm{In} X_{3}+3 \mathrm{LiNH}_{2} \rightarrow \mathrm{InN}+2 \mathrm{NH}_{3}+3 \mathrm{Li} X(X=\mathrm{Cl}, \mathrm{I})
$$

Reactions of $\mathrm{InCl}_{3}$ with $\mathrm{LiNH}_{2}$ resulted in samples containing In metal, even at temperatures well below the decomposition temperature of InN (Fig. 9). After reaction at $200{ }^{\circ} \mathrm{C}$ broad reflections are observed in addition to the In peaks, and these closely resemble the zinc blende-type GaN peaks. On raising the temperature, sharper peaks attributable to wurtzite-type (hexagonal) InN are observed, and on raising the temperature further to $500{ }^{\circ} \mathrm{C}$ only In metal is observed.

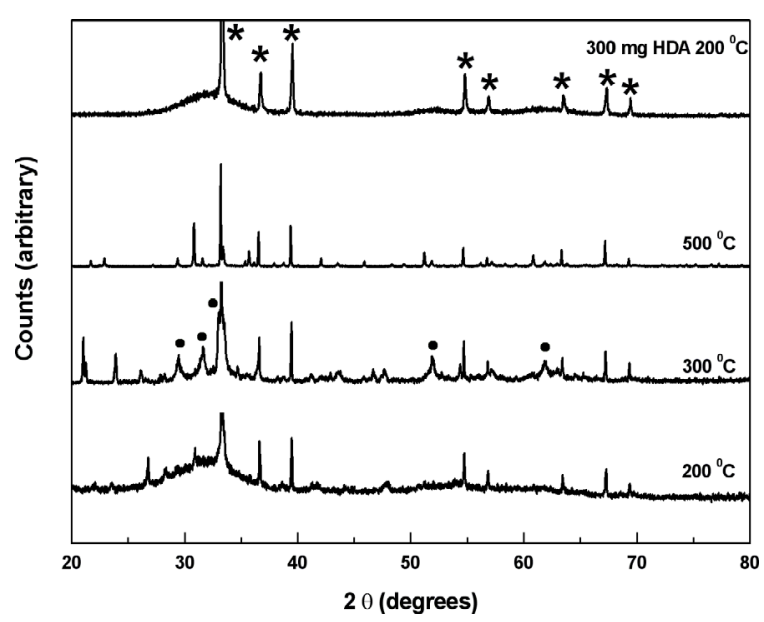

Fig. 9. XRD patterns of samples from solvothermal reactions of $\mathrm{InCl}_{3}$ with $\mathrm{LiNH}_{2}$ carried out at different temperatures. $\bullet=$ hexagonal InN; $*$ = In metal.

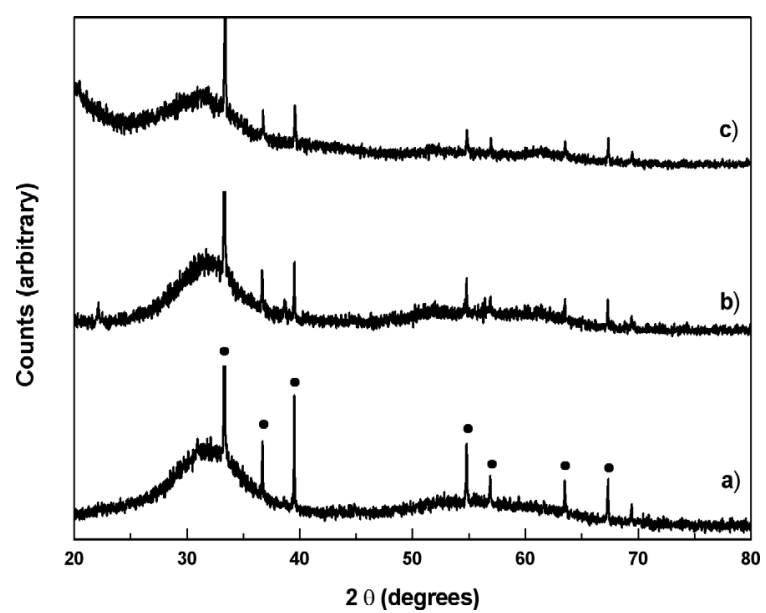

Fig. 10. XRD patterns of $\mathrm{InN}$ obtained from $\mathrm{InCl}_{3}$ and $\mathrm{LiNH}_{2}$ at $200{ }^{\circ} \mathrm{C}$ using: a) a $20 \%$ excess of $\mathrm{LiNH}_{2}$, b) a $50 \%$ excess of $\mathrm{LiNH}_{2}$, and c) a $100 \%$ excess of $\mathrm{LiNH}_{2}(\bullet$ marks peak positions attributable to In metal).

Addition of HDA to the low-temperature $\left(200{ }^{\circ} \mathrm{C}\right)$ reaction did appear to reduce the amount of In in the samples, but significant amounts were still formed.

An obvious way to reduce the amount of indium metal by-products in these reactions would be to increase the overall nitrogen content of the reaction mixture. Hence the effect of using an excess of the nitrogen source reagent, $\mathrm{LiNH}_{2}$, was investigated. Fig. 10 shows the effect of excess $\mathrm{LiNH}_{2}$. A small excess, $20 \%$, resulted in a reduction in the amount of In in the zinc blende-type InN products, but further additions of $\mathrm{LiNH}_{2}$ resulted in no further improvement and, 


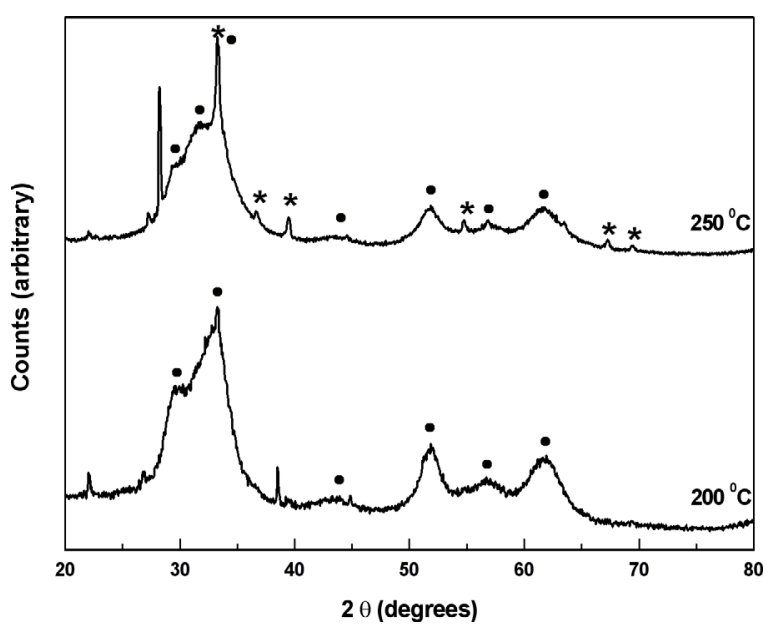

Fig. 11. XRD patterns of $\mathrm{InN}$ obtained using $\mathrm{InI}_{3}$ and $\mathrm{LiNH}_{2}$ at different temperatures. $\bullet=$ wurtzite-type InN, $*=$ In metal.

at $100 \%$ excess, amorphous scattering was observed in the diffraction pattern. Another option that has been reported by others [12] is the synthesis of InN from $\mathrm{InI}_{3}$ instead of $\mathrm{InCl}_{3}$. $\mathrm{InI}_{3}$ has a higher degree of covalent bonding than $\mathrm{InCl}_{3}$ and this has been argued as the reason why $\mathrm{In}^{3+}$ from $\mathrm{InI}_{3}$ is less liable to be reduced to elemental indium. Reactions of $\mathrm{InI}_{3}$ with $\mathrm{LiNH}_{2}$ resulted in wurtzite-type InN (Fig. 11). Some indium was still also present even at $200{ }^{\circ} \mathrm{C}$, and the amount increased at $250{ }^{\circ} \mathrm{C}$.

\section{Conclusions}

Solvothermal reactions of $\mathrm{GaCl}_{3}$ with $\mathrm{LiNH}_{2}$ are an effective method to produce nanocrystalline GaN. At $250{ }^{\circ} \mathrm{C}$, GaN forms with the zinc blende structure type, whereas at higher temperatures a mixture of zinc blende- and wurtzite-type phases forms. Addition of small amounts of hexadecylamine or $N$-cetyltrimethylammonium bromide surfactants to the lowtemperature reactions results in an increase in crystallinity, but aggregation of the particles is not fully inhibited. The analogous reactions with $\mathrm{InCl}_{3}$ produces InN, but this was contaminated with In metal even at reaction temperatures as low as $200{ }^{\circ} \mathrm{C}$. Use of excess $\mathrm{LiNH}_{2}$, or substitution of $\mathrm{InI}_{3}$ for $\mathrm{InCl}_{3}$, reduces the amount of In in the products, but does not eliminate it entirely.

\section{Acknowledgements}

This work was funded by the EU through an Early Stage Training Fellowship to P. C. and by Southampton Nanomaterials forum. Thanks to Prof. M. Weller for access to the X-ray diffractometer and to Dr. A. Page for training on the TEM.
[1] D. A. Neumayer, J.G. Ekerdt, Chem. Mater. 1996, 8, 9; H. Monkoc, S. Strilé, G. B. Gao, M.E. Lin, B. Sverdlov, M. Burns, J. Appl. Phys. 1994, 76, 1363; B. Garni, J. Ma, N. Perkins, J. Liu, T. F. Kuech, M. G. Lagally, Appl. Phys. Lett. 1996, 68, 1380; S. D. Lester, F. A. Ponce, M. G. Craford, D. A. Steigerwald, Appl. Phys. Lett. 1995, 66, 1249; F. A. Ponce, D. A. Bour, W. Götz, P. J. Wright, Appl. Phys. Lett. 1996, 68, 57.

[2] A.P. Purdy, Chem. Mater. 1999, 11, 1648; J. Jegier, S. McKernan, A. P. Purdy, W. L. Gladfelter, Chem. Mater. 2000, 12, 1003; D. R. Ketchum, J. W. Kolis, J. Cryst. Growth 2001, 222, 431.

[3] J. F. Janik, R. L. Wells, J. L. Coffer, J. V. St. John, W. T. Pennington, G. L. Schimek, Chem. Mater. 1998, 10, 1613; J.-W. Hwang, J. P. Campbell, J. Kozubowski, S. A. Hanson, J.F. Evans, W.L. Gladfelter, Chem. Mater. 1995, 7, 517.

[4] O. I. Mícíc, S. P. Ahrenkiel, D. Bertram, A. J. Nozik, Appl. Phys. Lett. 1999, 75, 478.

[5] B. Mazumder, A. L. Hector, J. Mater. Chem. 2009, 19, 4673; G. Demazeau, J. Mater. Sci. 2008, 43, 2104.

[6] J. B. Wiley, R. B. Kaner, Science 1992, 255, 1093; J. C. Fitzmaurice, A. Hector, I. P. Parkin, Polyhedron 1993,
12, 1295; J. C. Fitzmaurice, A. L. Hector, I. P. Parkin, J. Chem. Soc., Dalton Trans. 1993, 2435; A. Hector, I. P. Parkin, J. Chem. Soc., Chem. Commun. 1993, 1095; E. G. Gillan, R. B. Kaner, Chem. Mater. 1996, 8, 333; E. G. Gillan, R. B. Kaner, Inorg. Chem. 1994, 33, 5693; A. L. Hector, I. P. Parkin, Polyhedron 1995, 14, 913.

[7] Y. Xie, Y. Qian, W. Wang, S. Zhang, Y. Zhang, Science 1996, 272, 1926.

[8] C. Falter, M. Klenner, Q. Chen, Phys. Rev. B 1993, 48, 16690.

[9] Y. Zhang, J. Liu, R. He, Q. Zhang, X. Zhang, J. Zhu, Chem. Phys. Lett. 2002, 360, 579.

[10] K. Sardar, C. N. R. Rao, Adv. Mater. 2004, 16, 425.

[11] C. Wu, T. Li, L. Lei, S. Hu, Y. Liu, Y. Xie, New J. Chem. 2005, 29, 1610.

[12] Y.-J. Bai, Z.-G Liu, X.-G. Xu, D.-L Cui, X.-P. Hao, X. Feng, Q.-L Wang, J. Cryst. Growth 2002, 241, 189.

[13] J. Choi, E. G. Gillan, J. Mater. Chem. 2006, 16, 3774.

[14] B. Mazumder, A. L. Hector, J. Mater. Chem. 2008, 18, 1392; B. Mazumder, P. Chirico, A. L. Hector, Inorg. Chem. 2008, 47, 9684; P. Chirico, A. L. Hector, B. Mazumder, Dalton Trans. 2010, 39, 6092.

[15] PCPDFWIN (version 2.4), Powder Diffraction File, 
International Center for Diffraction Data, Swarthmore, PA (USA) 2003.

[16] A. C. Larson, R. B. Von Dreele, General Structure Analysis System (GSAS), report LAUR 86-748, Los Alamos National Laboratory 2004; B. H. Toby, J. Appl. Crystallogr. 2001, 34, 210.

[17] G. Socrates, Infrared and Raman Characteristic Group Frequencies, Wiley 2006, pp. 109-111.

[18] B.M. Gray, S. Hassan, A.L. Hector, A. Kalaji,
B. Mazumder, Chem. Mater. 2009, 21, 4210; A.W. Jackson, A. L. Hector, J. Mater. Chem. 2007, 17, 1016.

[19] S. Porowski, I. Grzegory, EMIS Datarev. Ser. 1994, 11, 82.

[20] S. Krukowski, A. Witek, J. Adamczyk, M. Bockowski, I. Grzegory, B. Lucznik, G. Nowak, M. Wroblewski, A. Presz, S. Gierlotka, S. Stelmach, B. Palosz, S. Porowski, P. Zinn, J. Phys. Chem. Solids 1998, 59, 289. 